\title{
MANAGEMENT OF ENDOCRINE DISEASE Can we cure Cushing's disease? A personal view
}

\section{Bertagna}

Service des Maladies Endocriniennes et Métaboliques, Centre de Référence des Maladies Rares de la Surrénale, Hôpital Cochin, Faculté de Médecine Paris Descartes, Université Paris 5, Paris, France

Correspondence should be addressed to X Bertagna

Email

xavier.bertagna@aphp.fr

\begin{abstract}
One of today's challenges in endocrinology is the treatment of Cushing's disease: Although pituitary surgery has the potential to 'cure' the patient and restore a completely normal pituitary adrenal axis, there are immediate failures and late recurrences that will ultimately require alternate therapeutic approaches. Their high number is in direct correlation with their serious limitations and they all appear to be 'default options'. This 'personal view' tries to shed some light on the inescapable difficulties of the current treatments of Cushing's disease and to provide some optimistic view for the future where the pituitary adenoma should be the 'reasonable obsession' of a successful therapeutist.

European Journal of Endocrinology

(2018) 178, R183-R200

'Je n'écris pas pour dire ce que je pense, mais pour savoir ce que je pense'1 Emmanuel Berl

\section{Introduction}

A rare disease (for how long?) now comes to the front stage.

Cushing's syndrome - and disease - recently became an unanticipated and favorite target for numerous new drugs. Chronic cortisol excess seems to inescapably attract

the appetite of many pharmaceutical companies that have suddenly identified a new 'Unmet Medical Need'.

Among the hypersecretory pituitary adenomas, the ACTH-secreting pituitary adenoma - beyond surgery indeed remains as an improbable frustration, resisting our current medical therapies. By comparison, PRL-,
\end{abstract}

\section{Invited Author's profile}

Xavier Bertagna is Professor of Endocrinology and has been the Chief of the Department of Endocrinology of Cochin hospital, Faculté de Médecine René Descartes, Université Paris 5, Paris, France. His research interest is in endocrine tumors, adrenal cancer, Cushing's syndrome, disorders of the pituitary-adrenal axis and polypeptide hormone precursors. He participates in all aspects of clinical care and research in these fields, from using new diagnostic tools to conducting therapeutic trials with innovative drugs, and particularly, developing translational research to elucidate the pathophysiological mechanisms of endocrine tumor formation and hormone hypersecretion.

\footnotetext{
${ }^{1 ' I}$ do not write to say what I think, but to know what I think.'
} Printed in Great Britain
Published by Bioscientifica Ltd.

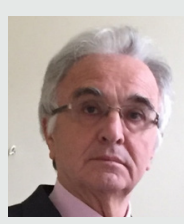


GH- and TSH-secreting pituitary adenomas have long found their brilliant 'medical solutions' with dopaminergic-somatostatin (SST) analogs, and even indirectly - growth hormone (GH)-receptor antagonists.

In contrast, the ACTH-secreting pituitary adenoma is still somewhat an orphan with regard to targeted therapeutic approaches. A stimulating orphan, pushing numerous investigators and pharmaceutical companies, to explore all possible therapeutic strategies against the many actors, which compose the pituitary-adrenalglucocorticoid receptor (GR) axis. (1).

They often succeed in reducing the 'chronic hypercortisolism'. Lasting restoration of a 'normal' pituitary adrenal axis, however, is another question. The 'holy grail' for Cushing's disease is yet to be found.

\section{You said... 'cure'}

On theoretical and practical grounds, several criteria should be met simultaneously to assume that we have 'cured' a patient with Cushing's disease.

\section{Suppressing the 'chronic hypercortisolism'}

Cushing's syndrome - and disease - is defined by an array of signs and symptoms and possible complications induced by chronic excess of circulating free cortisol ('chronic hypercortisolism'). There are different ways to assess 'chronic hypercortisolism', the most widely used is to measure cortisol in a 24-h urinary collection (urinary cortisol or UC). Thus, any treatment should, at least, decrease UC under its upper limit of normal (ULN). And almost all therapeutic trials, these days, use this purely biochemical target as their primary end point.

\section{Restoring a normal pituitary-adrenal axis}

In contrast with other pituitary functions, like prolactin, for example, the objective here is not only to suppress the hypersecretion. It is also to restore the day-to-day fine tuning of normal cortisol secretion: not only should UC be in the normal range, but plasma cortisol should resume its normal circadian pattern, with normal early morning and late evening values, and the overall pituitary-adrenal axis should regain its ability to react to stress.

However, few, if any, of the current medical approaches will offer such an outcome.

\section{Correcting the clinical peripheral features/complications of 'chronic hypercortisolism'}

Anticipating the beneficial effect(s) of suppressing the 'chronic hypercortisolism' is indeed a difficult task. It is not always easy to answer the patient's questions:

- 'Shall I lose weight?'

- 'Shall I resume my menses?' 'When?'

- 'How about my excess hair, diabetes, high blood pressure, osteoporosis...?'

On a semantic point of view, should we discriminate between signs and symptoms, clinical features, metabolic abnormalities and complications? Is secondary amenorrhea a 'clinical feature' associated with 'chronic hypercortisolism' or a complication of hypercortisolism leading to infertility? We encounter the same question when looking at diabetes, high blood pressure, osteoporosis and central nervous system (CNS) disturbances in the context of 'chronic hypercortisolism'.

It is of obvious clinical experience that features/ complications are not of equal significance and clinical impact: after successful treatment, diabetes may disappear within days, menses resume within weeks and height loss due to vertebra collapse ... never.

Age of the patient and duration of the 'chronic hypercortisolism' are also important factors, which determine the reversibility - or irreversibility - of the complications:

- Tissue plasticity is a remarkable advantage in young individuals, which helps restore normal skin, muscle and bone mass. (Fig. 1). The best example of it is the 'catch-up' growth of children after cure of Cushing's syndrome.

- Long-standing 'chronic hypercortisolism' may create irreversible damage, particularly of the cardiovascular system.

Finally, the 'pre-Cushing' situation should ideally be taken into consideration: many - most - clinical features induced by 'chronic hypercortisolism' are fairly common and often present in individuals without (before?) Cushing's disease: obesity, diabetes, high blood pressure, CNS disturbances, osteoporosis. It is not always possible to evaluate, in a given patient, how much cortisol excess by itself contributes to the overall clinical presentation ('La part du cortisol', Fig. 2).

Furthermore, individual subjects are not equal when confronted with 'chronic hypercortisolism' and 

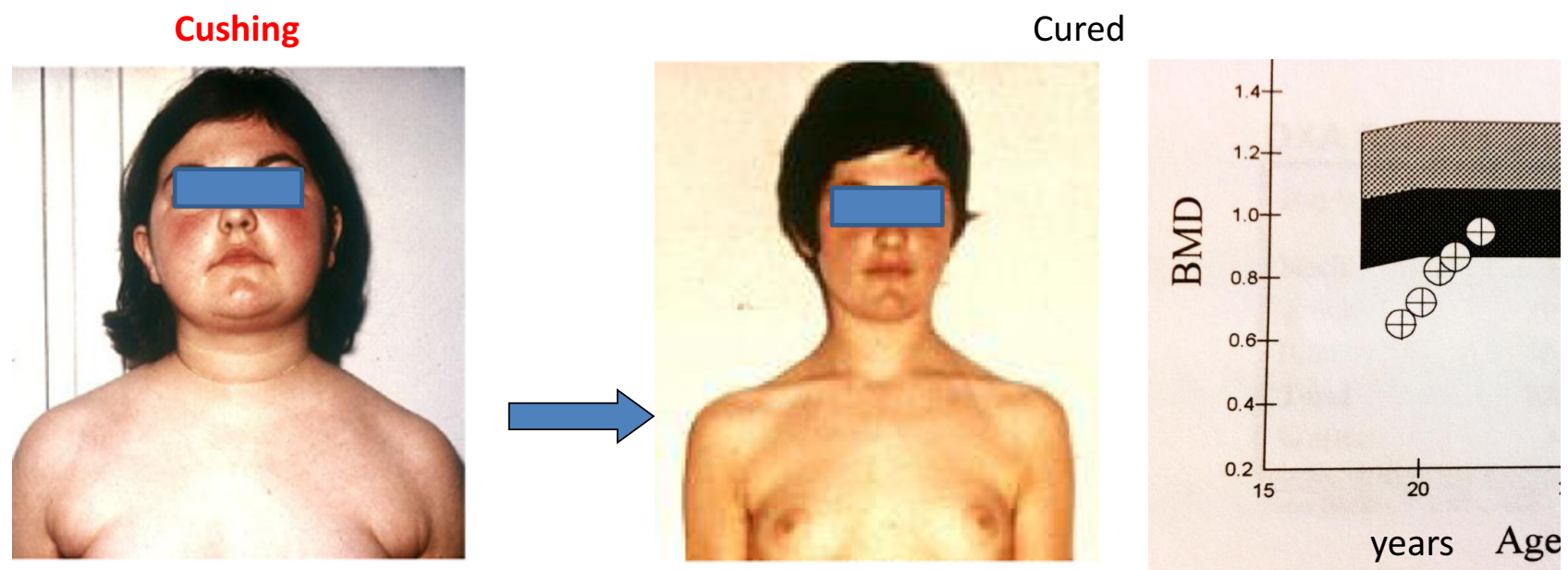

Figure 1

Reversibility of peripheral clinical features after controlling the 'chronic hypercortisolism'. Morphotypic features and bone loss, are impressively reversed after the hypercortisolism is controlled in young patients. BMD, bone mineral density.

within one individual, organs are not equal either: one individual will develop osteoporosis and no diabetes, the other diabetes and no osteoporosis.

\section{Ablating the responsible tumor}

In Cushing's syndrome, whatever its cause, we always have two enemies, which are invariably present together at the same time: a hormone, cortisol and a tumor, which causes - directly or indirectly - overproduction of cortisol.

Anatomical constraints and tumor invasion into difficult to access adjacent tissues do not always allow to easily completely ablate the responsible tumor, ruling out the ideal possibility of suppressing the two 'enemies' at the same time by a unique, efficient and definitive approach.

In Cushing's disease, treatments at the level of the adrenals (bilateral adrenalectomy, steroid inhibitors, adrenolytic, antiglucocorticoids) can efficiently control the 'chronic hypercortisolism'. While bilateral adrenalectomy is a definitive 'cure' of tumor-driven adrenal cortisol excess, drugs inhibiting steroid synthesis or action are generally not a reliably long-term therapy. Yet, we should always keep in mind that the causal tumor, is still there, and can grow further. The same is true for occult ACTH-secreting ectopic, non-pituitary tumors and even for adrenocortical cancer after surgery of the primary tumor. It is a highly frustrating situation when one observes the great and immediate clinical benefit in a young female just operated from a highly hypersecretory adrenocortical cancer and already detects rapidly growing pulmonary metastases. The patient feels the good of the operation when the doctor, at the same time, foresees the premises of the catastrophe.

\section{Ideally}

Not only is the definition of 'cure' rather stringent, but also the way to obtain it: It should avoid side effects, minimize the risk of recurrence, be cost-effective, easily performed, have a high success rate, a rapid delay of action, a large availability worldwide.

\section{Yes we can...sometimes!}

The only way to 'cure' Cushing's syndrome - whatever its cause - is SURGERY.

\section{Who can be cured?}

As stringent as they may be, conditions for 'cure' can be met. We will consider here the whole spectrum of Cushing's syndrome with all its causes.

Two conditions should be met:

The tumor can be entirely and definitively removed (neither invasive nor 'occult', and benign)

The unilateral cortisol-secreting adrenocortical adenoma (always) The tumor is visible, non-invasive, benign and can always be surgically removed entirely with no risk of recurrence. The suppressed pituitary corticotroph function will resume spontaneously, if after some delay. In the context of 

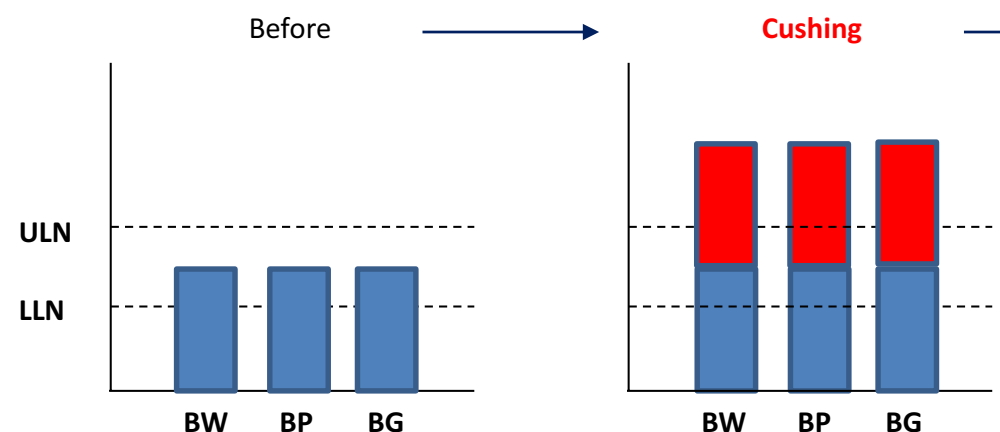

Cured
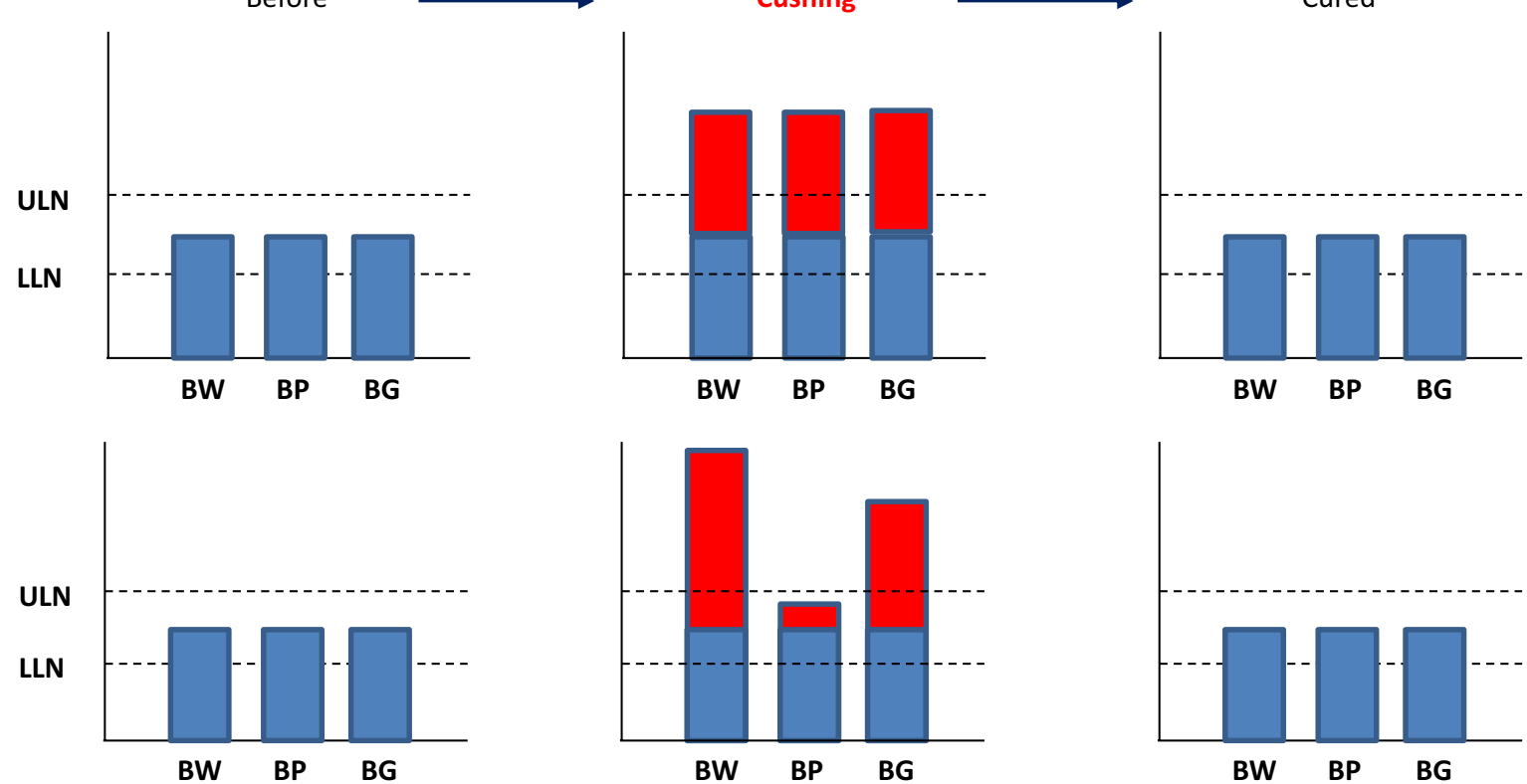

Patient 2

Patient 3
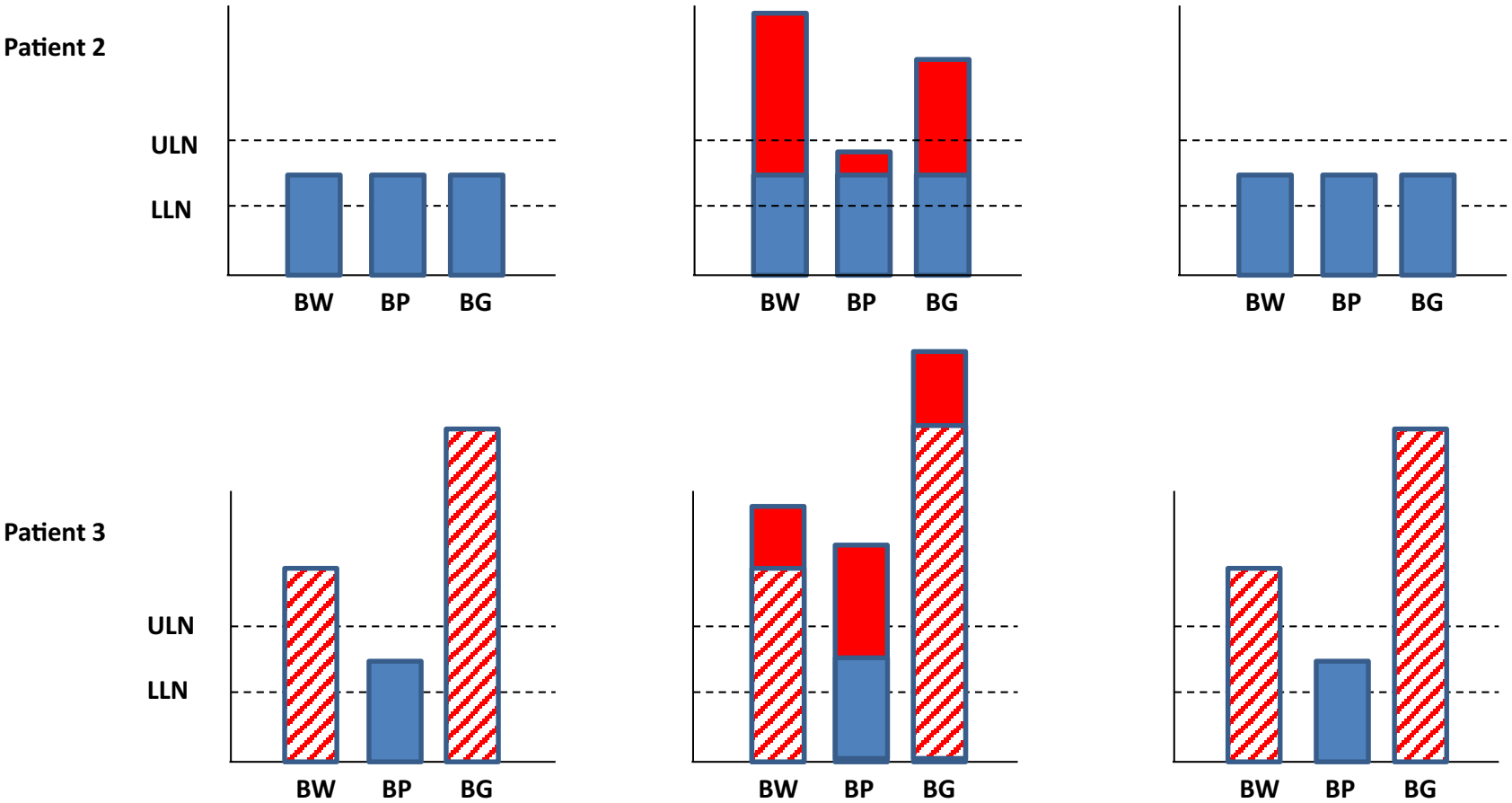

Figure 2

'La part du cortisol'... 'cortisol contribution'. Three common clinical parameters, body weight (BW), blood pressure (BP), and blood glucose (BG) are schematically followed before-, during- and after 'cure' of 'chronic hypercortisolism', in three 'schematic' patients, with normal - (upper, and middle) or already abnormal (lower) clinical parameters before the occurrence of the hypercortisolism. It shows that assessment of cortisol contribution to the overall clinical picture would require to know the pre-disease state, assuming a complete reversal of the clinical features induced by 'chronic hypercortisolism'.

Cushing's syndrome, the adrenal cortical adenoma is certainly the best thing one can have.

The ACTH-secreting pituitary adenoma of Cushing's disease (often) The tumor is almost always benign and can often be surgically removed entirely. Yet, it is not always visible, or it can be invasive, explaining that failures and/or recurrences are common.

In case of 'immediate success', the suppressed pituitary corticotroph function will resume spontaneously, if after some delay.

It is a remarkable situation where partial resection of a gland actually boosts back its overall function: this is obvious, for example, when menses spontaneously resume after partial hypophysectomy.

The non-pituitary tumor responsible for ectopic ACTH secretion (rarely) Non-pituitary tumors responsible for ectopic ACTH secretion are often malignant and not amenable to surgical cure (small-cell carcinomas of the lung).

Rarely can they behave as very indolent tumors, displaying almost benign outcomes despite their malignant character, e.g. bronchial carcinoid tumors, which can be cured surgically if detected early and not 'occult'. The latter nevertheless require careful follow-up 
as metastases can occur and complicate the course of disease.

The adrenal cortical carcinomas (very rarely) These are usually very aggressive tumors with dismal prognosis and several series have highlighted tumor-related cortisol secretion as an unfavorable prognostic factor.

Very rarely, early diagnosis of a localized tumor (stage 1-2) allows surgical 'cure' with long term, if not definitive remission.

The bilateral benign ACTH-independent adrenal cortical hyperplasia syndromes (almost never) These benign, but almost always bilateral lesions, seen in the McCune-Albright syndrome, the Carney complex, the AIMAH syndromes are almost inevitably treated by bilateral adrenalectomy. Although the 'chronic hypercortisolism' is always easily corrected, restoring normal pituitary adrenal axis is evidently impossible. An exceptional patient with a highly asymmetrical form may be 'cured' (transiently?) by a unilateral adrenalectomy.

In all these cases, as stated earlier, a second condition is necessary if the complete definition of 'cure' must be respected.

\section{Surgery must be done before irreversible complications of 'chronic hypercortisolism' occur}

Restoring a normal pituitary-adrenal axis is not sufficient for 'cure'. The sooner the diagnosis and the control of hypercortisolism, the higher the probability to correct the peripheral features/complications of the 'chronic hypercortisolism'.

\section{Pituitary surgery: 'La voie royale'... when it works}

As anticipated from the title, the following discussion is now restricted to Cushing's disease, i.e. an ACTHproducing pituitary adenoma as the cause of Cushing's syndrome.

\section{Pituitary surgery: 'La voie royale'}

\section{Nothing as good}

Few situations are as rewarding as 'curing' a young female patient from the unbearable features of Cushing's syndrome through a 30-min pituitary surgery. Within hours, cortisol plasma values drop to undetectable, and within months, the overall pituitary adrenal axis will return to normal: the daily circadian variations of serum cortisol, the response to any dynamic tests (suppression or stimulation) will all be undistinguishable from those in normal subjects.

The various features/complications that have accumulated whilst the patient was exposed to 'chronic hypercortisolism' will disappear, at different rates, more or less completely (see above and Fig. 2).

It is not exceptional that young patients who have had an early diagnosis achieve recovery to an overall clinical situation that is indistinguishable from normal.

\section{When it works}

'Une voie royale...semée d'embuches!' The pituitary surgery is indeed the 'royal approach ... but full of pitfalls!'.

Considering the size of the pituitary gland, its deep location at the base of the brain, embedded in a semiconfined osseous structure, a few millimeters from vital structures like the carotid artery...it has always been something close to a miracle for me that neurosurgeons can find a tiny adenoma, distinguish it from the normal surrounding gland, resect it entirely, obtain the pathological confirmation and respect/restore the integrity of all anterior pituitary functions (Fig. 3).

Because very small adenomas are not always found, because invasive adenomas cannot always be resected entirely, the pituitary surgery is not always a 'royal approach': immediate failures and late recurrences do occur.

Although many studies have analyzed the many possible features that could be predictive of pituitary surgery success, such as age, sex, duration of disease, degree of hypercortisolism, responses to different dynamic tests, it is actually - and quite logically - the anatomical conditions of each adenoma, together with the surgical skills, that are the dominant parameters. Removing a pituitary adenoma is more complicated than removing an adrenal cortical adenoma!

Full pathological examination of all the removed pituitary fragments is seminal and should not use any shortcuts: in case of immediate failure a positive histology can give the ultimate proof that we are not merely misdiagnosing another source of non-pituitary ACTH; it raises some doubt on the completeness of the surgery if only tumoral cells are found; for these reasons, it may be ethically questionable to collect 'some' fragments for research aims and scientifically questionable to believe that these fragments can be homogeneous; these latter technical reasons may explain the difficulties of 


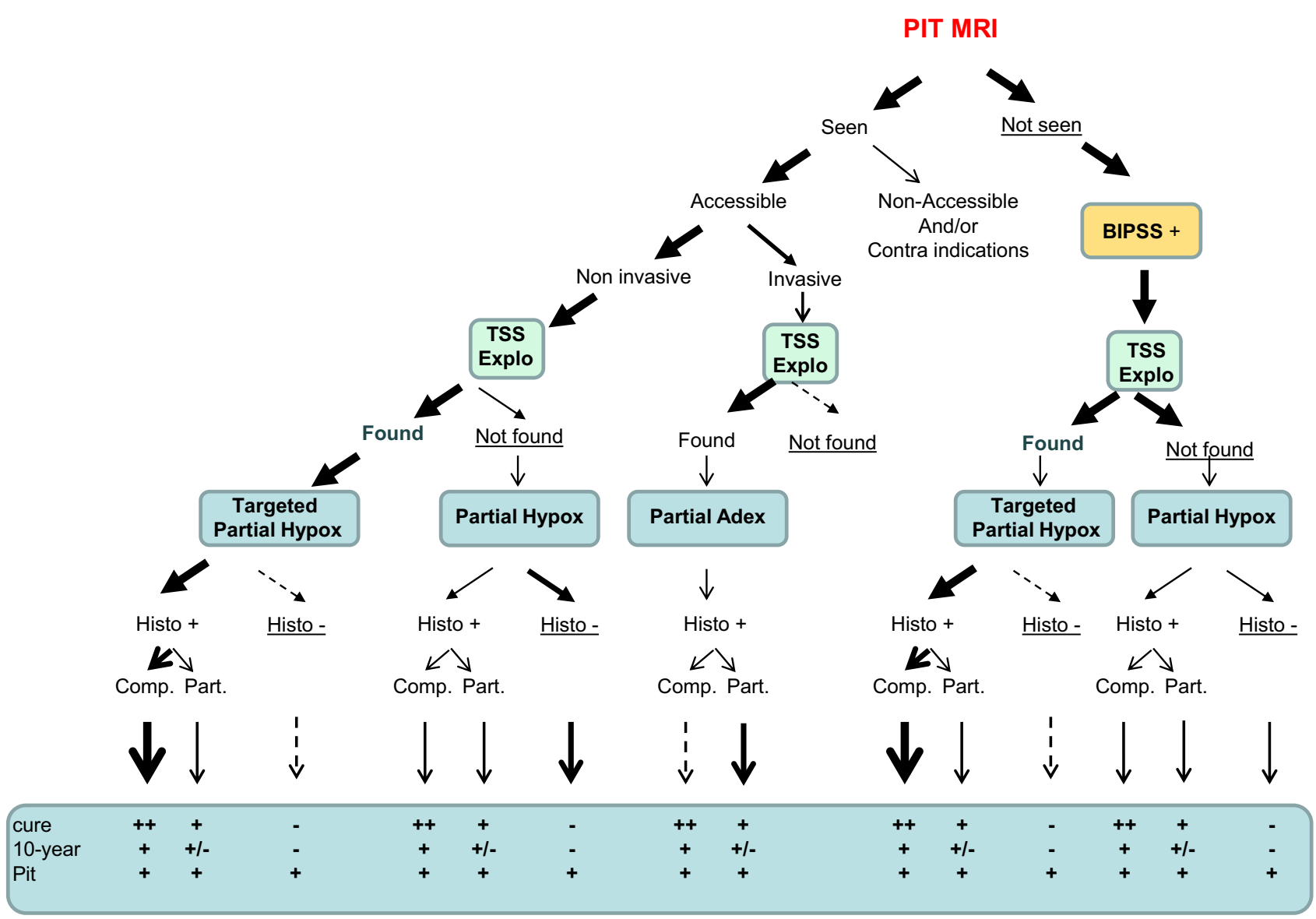

Clinical outcome

Figure 3

Pituitary surgery, 'la voie royale' ... 'the royal approach'. This scheme resumes the determinants of a successful pituitary surgery, which authorize that a partial hypophysectomy (Hypox) will remove the entire pituitary adenoma and lead to long-lasting (definitive) cure, while preserving the overall anterior pituitary function, as shown by the outmost series of arrows on the left ('La voie royale'). This is but one pathway, among many others, also shown. 10-year, lasting control of hypercortisolism after pituitary surgery at 10 years; BIPSS, bilateral inferior petrosal sinus sampling; cure, immediate control of hypercortisolism after pituitary surgery; Comp., complete removal of the pituitary adenoma; Histo + or -, positive or negative immunohistochemistry for ACTH in surgically removed pituitary tissue; Part., partial removal of the pituitary adenoma; Partial Adex, partial surgery of the pituitary adenoma; Pit, preserved overall anterior pituitary function; Pit MRI, pituitary magnetic resonance imaging; TSS explo, transsphenoidal surgery exploration.

transcriptomic approaches in ACTH-secreting pituitary adenomas.

And yet, even in case of failure, the beauty of the pituitary surgery is that nothing irreversible has been done: all other options remain possible, including a second surgery.

Taking a historical view, we should certainly be indebted to the Mayo Clinic (2) and San Francisco (3) teams and their iconic efforts, in the late 1970s, to engage in pituitary surgery of Cushing's disease patients, a time when science (and experts) were pointing out, in the highest ranked journals, the 'possible' causal role of the hypothalamus (4).

\section{All other therapeutic approaches are 'default options'}

When pituitary surgery has failed, or is judged not feasible, the endocrinologist is not deprived of other therapeutic options. On the contrary, he has too many, which is never a straightforward or desirable situation. 
Medical treatment targeting the pituitary (dopaminergic, SST analogs), the adrenal cortex (inhibitors of synthesis, adrenolytic), the glucocorticoid receptor (Mifepristone), pituitary radiotherapy, and, eventually bilateral total adrenalectomy...all are associated with inescapable limitations:

- They almost always create a second (and sometimes third) disease:

- Addison's disease with the adrenolytic Mitotane or after bilateral adrenalectomy.

- Adrenocortical blockade with inhibitors of steroid synthesis, and the problems of excess precursors, fine tuning of daily dosage, risk of adrenal insufficiency.

- The inescapable features of general resistance to glucocorticoids (excess androgen, mineralocorticoids), and even a third one (progesterone blockade) with Mifepristone. And the many difficulties to adapt the treatment (see below).

- Pituitary insufficiency with radiotherapy

- Leaving the first disease, the pituitary adenoma, with its own propension to grow, if not irradiated.

- Often add adverse events (AEs)

- Diabetes is a big concern when using Pasireotide.

- Significant gastrointestinal and CNS AEs, and many other possible side effects with chronic Mitotane treatment.

- Never restore a normal pituitary-adrenal function

- None of these approaches can restore a normal pituitary-adrenal axis.

- Reduce/eliminate the 'chronic hypercortisolism'... most often

- Apart from total bilateral adrenalectomy - which does not have a unexpected rate of success of $100 \%$ - all other therapeutic options have much lower success rates to control the 'chronic hypercortisolism'.

\section{The 'inescapable' limitations of the medical treatments}

Assessing the efficacy of any therapeutic option in Cushing's disease patients is difficult due to the nature of the disease; and this is particularly true when new medical options are tried:

- It is difficult to recruit a large number of patients with a rare disease.

- UC is a logical primary end point. Yet, it has limitations: to recruit more patients, it is useful to have cases with mildly elevated UC, down to 1.5 -fold ULN, a range where spontaneous fluctuations may simply normalize UC. Surprisingly, some studies also assess the efficacy of a treatment, counting patients whose UC remains above the ULN, but is reduced by half or more in comparison to its baseline value. Something rather controversial, knowing the large spontaneous variability of UC in Cushing's disease patients (5), and when the same authors state in parallel publications that the 'degree' of hypercortisolism is not related to its severity (6).

- Because of these specific features, it would be particularly important to design 'well-controlled' trials. However, because of the supposed intrinsic severity of Cushing's disease, most - if not all - therapeutic trials carried out so far have been uncontrolled.

- Whereas it is logical to measure UC as the primary end point, the patients actually complain of the peripheral consequences...not 'UC'! These latter features (obesity, diabetes, high blood pressure, gonadal dysfunction) are more difficult to evaluate, also because they are most often treated symptomatically, and one may have to evaluate, as precisely as he or she can, the decrease in the need to medically manage the treatment of Cushing-related clinical consequences/complications.

\section{Medical treatments towards the pituitary adenoma}

- PasireotideThe somatostatin (SST) analog is assumed to act directly at the level of the pituitary adenoma, through the SST2 and SST5 subtype receptors, inhibiting tumor ACTH secretion.

- Yet,

- Close to $80 \%$ of patients have 'hyperglycemia' and/or develop or worsen diabetes. This is highly undesirable in these patients, who may even require the addition of a supplemental antidiabetic treatment whilst receiving treatment that is meant to improve their clinical situation.

- Cholelithiasis may occur.

- Only between 25 and $40 \%$ of the patients achieve normal UC (7). Not unexpectedly, the figures become better when considering only patients with 'mild' Cushing's disease or counting those patients who did not normalize but dropped their initial UC by more than 50\%. Raising two new questions:

- What is 'mild' Cushing's disease? UC value is not the only determinant to the severity of Cushing's disease.

- Is it better to have mild, untreated, Cushing's disease without diabetes or normal UC with 
diabetes? Is it better to have mild, untreated, Cushing's disease or normal UC with cholelithiasis?

- What is the rationale of the 50\% decrease in UC as a therapeutic target (see upper)?

\section{Cabergoline}

- The dopamine agonist is supposedly acting directly at the pituitary adenoma, through the D2 receptor subtype, inhibiting tumor ACTH secretion.

- Yet,

- The efficiency rate seems to be rather low. Several studies have reported that this dopamine D2 receptor agonist can normalize UC in about 30\% of Cushing's disease patients. For unknown reasons, some patients seem to escape this therapeutic response after a few months of treatment (8).
- Other than the adverse effects common to all dopaminergic drugs, it is generally well tolerated.

\section{Medical treatments targeting the adrenal cortex}

Inhibitors of steroid biosynthesis While all these drugs can evidently lower - and even - control the cortisol oversecretion, their modes of action inescapably create serious drawbacks.

- Metyrapone and LCI 699.

- Both drugs directly inhibit the major cortisol-producing CYP11B1, blocking the conversion of 11-deoxycortisol to cortisol and thereby lowering the adrenals' ability to overproduce cortisol $(9,10)$.

- YET:

- These chronic treatments transform a patient with Cushing's disease in another patient with now two

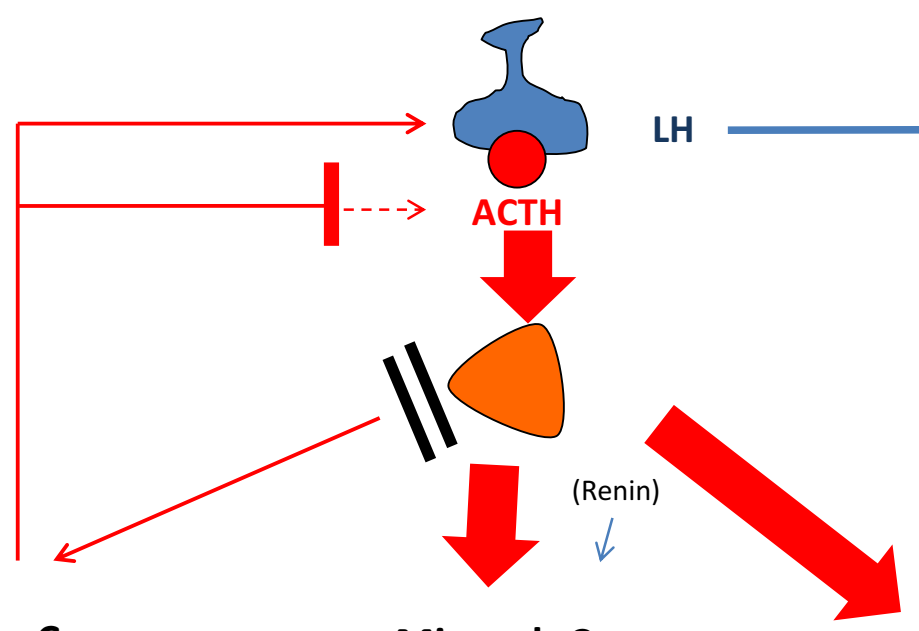

GlucoCor. (Cortisol)

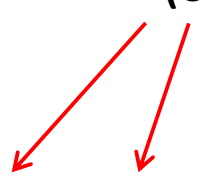

Fat

Sugar

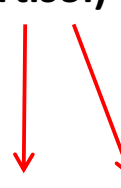

Protein Immunity CNS
MineraloCor.

(DOC/Aldo)

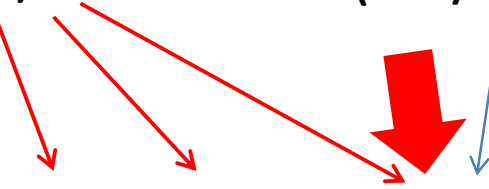

Salt

HBP

K

Vessels

Balance?
Infection Depression

Muscle.

Improved/Cured

\section{Figure 4}

The hormone turmoil of CYP11B1 blockade in Cushing's disease and its peripheral consequences. The beneficial decrease of cortisol inescapably increases ACTH plasma levels, with consequences on both mineralocorticoids and androgens. 
diseases: CYP11B1 blockade plus a pituitary ACTHsecreting adenoma.

- As exemplified in Fig. 4, the overall result may associate better cortisol control with worsening androgen in females and mineralocorticoid excess in both sexes. What will be the ultimate balance?

- The challenge of drug dosage adjustment:

- A 'titrating' approach is proposed where the doctor has to administer the appropriate dose of drug, daily to the patient, without supplemental glucocorticoid: The concept, here, is to find exactly the right dose of medication that will chronically normalize UC of a given Cushing's disease patient. This approach has serious limitations (Fig. 5):

- How to cope with spontaneous fluctuations of daily cortisol production of Cushing's disease patients (5)?

- Normal UC does not mean normal pituitary adrenal axis.
- The normal circadian rhythm cannot be restored (see further).

- How about the response to stress in these patients? Will ACTH rise? Which $\mathrm{ACTH}$, that from the tumor or that from the reactivated peri-tumoral normal corticotroph cells? If so, will the adrenal cortex be responsive enough?

- How to recognize/avoid adrenal insufficiency (AI)?

- Clinical judgment is key. Yet, the clinical manifestations are not very specific, particularly if we want to make an early diagnosis of AI, and not wait for acute $\mathrm{AI}$ (vomiting, abdominal pain, brisk blood pressure drop, electrolytes changes...).

- Early and mild AI will be suspected each time a patient will complain of 'not feeling well'. Many symptoms like fatigue and stomach discomfort are just completely non-specific; decreased blood pressure

\section{Plasma \\ (salivary) \\ cortisol (F)}

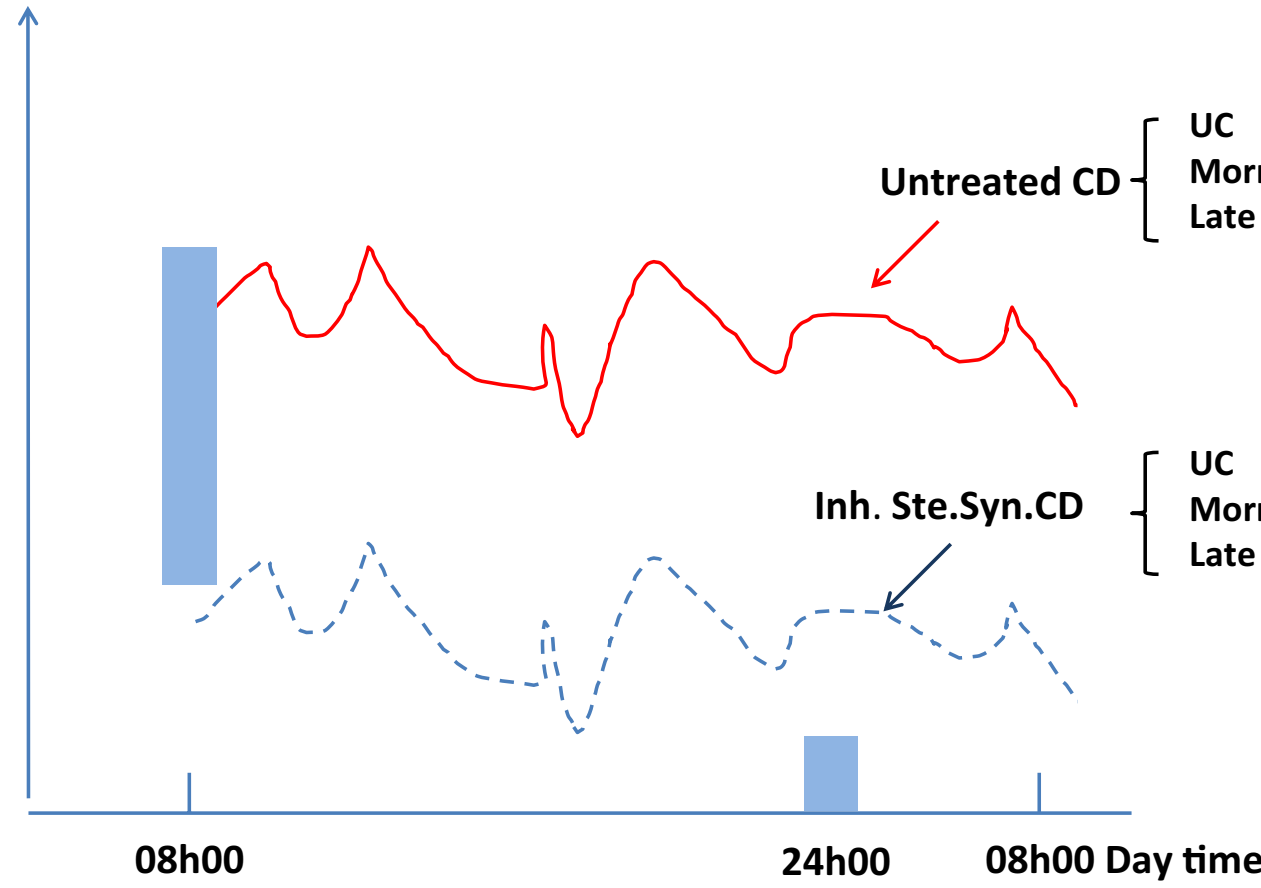

Figure 5

The titrating approach. The theoretical continuous plasma levels of cortisol in an untreated Cushing's disease patient (solid line) and in a patient under an inhibitor of steroid synthesis administered symmetrically twice a day (dotted line). Normal early morning (08h00) and midnight cortisol ranges are indicated. F, cortisol; UC, 24-h urinary cortisol. 
might not help so much since it could possibly be a benefit of the treatment and some patients still on antihypertensive drugs

- Measuring cortisol levels does not really help: Because some patients have symptoms that look like AI but have normal cortisol levels, some will invoke the ill-defined label 'cortisol withdrawal syndrome'. And the reverse also happens, patients with low plasma cortisol and no complaints! Furthermore, under a titrating approach, there is not something as a 'normal range' for plasma (and/or salivary) cortisol levels. Although cortisol production is partially hampered by the treatment, it is still driven by the tumor ACTH, and thus, fairly stable in the day. It was anticipated that obtaining a normal
UC would be at the expense of 'low' early morning serum (salivary) cortisol and 'high' late night serum (salivary) cortisol (Fig. 5), as confirmed in Fleserius' paper (11).

- A 'Block and replace' approach is alternatively proposed: here the doctor administers a large dose of medication, to the point that cortisol secretion is totally suppressed, and the patient is supplemented with cortisol (Fig. 6):

- The advantages:

- We do not have to wonder whether or not the patient is in AI...he (she) is.

- We eliminate the problem of day-to-day fluctuations of the endogenous cortisol.

- We can restore not only a normal UC but also a normal - although artificial circadian rhythm, by properly adjusting the cortisol supplementation schedule.

\section{Plasma \\ (salivary) cortisol (F)}

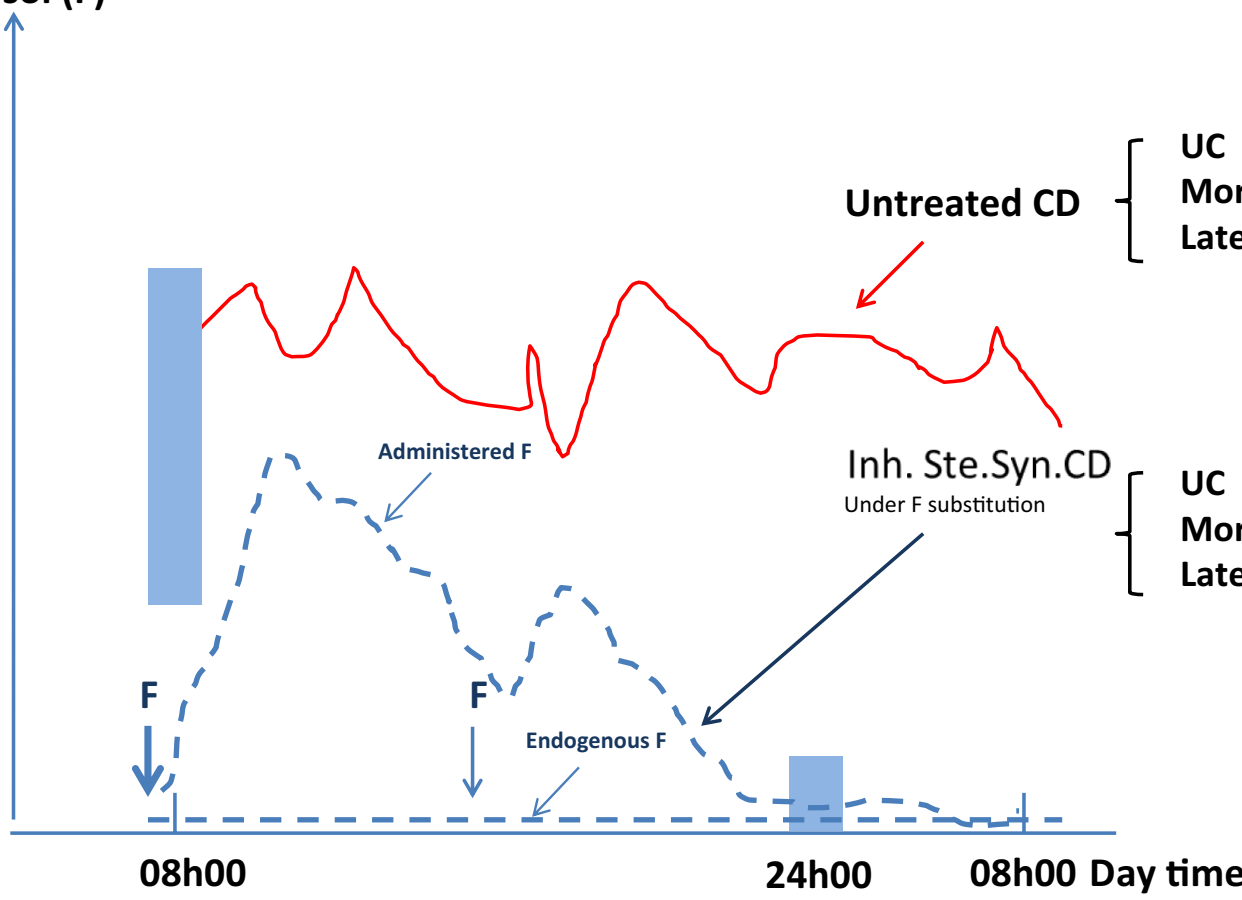

Figure 6

The block and replace approach. The theoretical continuous plasma levels of cortisol in an untreated Cushing's disease patient (solid line) and in a patient under an inhibitor of steroid synthesis administered symmetrically twice a day (dotted line) and supplemented with cortisol in the morning and at noon (arrows). Normal early morning (08h00) and midnight cortisol ranges are indicated. F, cortisol; UC, 24-h urinary cortisol. 
- The drawbacks:

- The inescapable AI, even if it is purposely created.

- CYP11B1 inhibition will induce higher levels of precursors, mineralocorticoids and androgens in women - as exemplified by patients with inactivating CYP11B1 mutations, causing congenital adrenal hyperplasia due to 11-beta-hydroxylase deficiency.

- Ketoconazole.

- The drug directly inhibits several enzymes mostly at the start of the overall steroid biosynthetic pathway, lowering the adrenals' ability to produce cortisol (12).

- Yet,

- This chronic treatment transforms a patient with Cushing's disease in another patient with now two diseases: 'high' blockade of steroid biosynthesis plus a pituitary ACTH-secreting adenoma!

- Because the blockade is situated early on in the steroid biosynthetic pathway, the problem is no more that of potential excess of deleterious biologically active precursors of cortisol, but rather that of a 'spillover' mechanism where the drug can decrease all steroid synthesis including into the gonads, particularly the androgens.

- As with Metyrapone and LCI699, the same problems are encountered with the drug adjustment, whether we use the 'Titrating' or the 'Block and replace' approaches.

\section{The adrenolytic Mitotane}

- Mitotane induces long-lasting adrenolytic action through a recently found mechanism (13) involving increased apoptosis due to accumulation of free cholesterol ester in steroid-secreting adrenocortical cells. Its rather specific action at the adrenal seems to be in correlation with its action being exquisitely directed against ACAT 1 , which is found predominantly in the adrenal cortex. Mitotane suppresses the hypercortisolism in a majority of patients, ca. 80\% (14).

- Yet,

- It has a slow onset of action and a highly variable bioavailability.

- It will most often induce a state of 'chemical adrenalectomy', with a mandatory need for corticosteroid supplementation, the adjustment of which is rendered difficult in face of altered steroid transport and metabolism. Mitotane induces CYP3A4-mediated rapid inactivation of cortisol (15), which means that patients require a 2- to 3 -fold increased cortisol replacement dose.

- Through strong inhibition of androgen activation by 5-alpha-reductase activity (15), male patients develop hypogonadism that requires 5a-dihydrotestosterone rather than testosterone replacement.

- Although its efficacy may last for years in a given patient, the benefits are most often only transient.

○ It has numerous AEs (16).

\section{Medical treatment targeting the glucocorticoid receptor: Mifepristone}

- Mifepristone (RU 486), originally developed as an anti-progesterone drug (and presently used in many countries as a contragestive), was also found to be an anti-glucocorticoid drug potentially active in man (17).

- Several papers had initially suggested that it could be efficacious in occasional cases of Cushing's syndrome, including patients with Cushing's disease.

- The first systematic approach was recently performed in USA: the SEISMIC study selected adult patients with various causes of Cushing's syndrome and type 2 diabetes mellitus or hypertension. Among them, 42 patients had persisting Cushing's disease after failure of pituitary surgery (18). A single oral dose of mifepristone, between 300 and $1200 \mathrm{mg}$ per day, was administered for 24 weeks, in an open-label, multicenter study design. A clear benefit was obtained towards some peripheral features in relation to cortisol action: Mean body weight dropped 5.7\%; insulin resistance decreased, glucose metabolism was improved, as well as cognition and quality of life. This original therapeutic approach, opposing glucocorticoid action, indeed showed some efficacy.

- Yet,

- Given the mode of action of the drug and the pathophysiological mechanism of ACTH oversecretion in Cushing's disease, several problems had long been anticipated:

- How to evaluate the treatment efficacy when endogenous cortisol becomes meaningless (UC actually increased sevenfold on average in response to long-term mifepristone administration)?

- How to monitor drug dosage, when we can only make clinical judgment on the peripheral - and rather non-specific - actions of cortisol? 
- How to recognize and diagnose adrenal insufficiency, and to treat it, in the presence of high circulating cortisol levels?

- How to avoid the possible side effects induced by the inescapable and chronic ACTH increase and the mineralocorticoid actions of both increased cortisol and 11-deoxycortiosterone (DOC) that can act at the mineralocorticoid receptor and thereby, if un-opposed, will be creating hypokalemia and edema?

- How to cope with the antiprogesterone action of mifepristone in women, its adverse events on uterus myometrium, and of course being non-compatible with planned pregnancy?

\section{With all medical options}

- None of these medical options can restore a normal pituitary-adrenal axis.

- Even in those patients whose hypercortisolism is controlled, a normal axis is not restored (that would include no risk of adrenal crisis, normal circadian rhythm and normal response to stress).

- Asymmetrical administration of steroid inhibitors might be of help: Metyrapone given at the end of the day further lowers the morning nadir of cortisol plasma values in the particular situation of adrenal incidentalomas with no Cushing's syndrome but some autonomous cortisol secretion (19).

- A fairly large array of specific AEs.

- The need to carefully follow the potential growth of the pituitary tumor.

- The contraindication in pregnant female.

- A variable success rate.

- The necessity for a life-long treatment?

\section{The inescapable limitations of pituitary radiotherapy}

- Pituitary radiotherapy may control ACTH oversecretion, as well as tumor growth. It can be performed either classically by conventional fractionated radiotherapy or by stereotaxic radiosurgery (gamma knife or proton beam therapy) (20).

- Yet,

- In all cases, its action on the tumor proceeds slowly, and success rates for controlling the 'chronic hypercortisolism' vary widely between series, depending on the doses administered and the duration of follow-up. It is rarely better than $50 \%$ at two years, although it further progresses with time. There is no clear evidence that better outcome is obtained with the stereotaxic radiosurgery approach. Therefore, it is not a good option when a rapid cure is needed, at least when used alone. In many cases, radiotherapy has been combined with medical therapy, usually inhibitors of steroid synthesis.

- Also, with radiotherapy the normal pituitary tissue is not 'spared', and failure of some pituitary functions occurs in up to $50 \%$ of the patients. There is no evidence that stereotaxic radiosurgery minimizes this adverse effect.

- Finally, a potential risk of cerebrovascular complications has been reported, although these are probably lower with modern radiotherapy techniques.

\section{The inescapable limitations of bilateral adrenalectomy}

- The major advantage of this surgical option is its unequaled efficacy to control the 'chronic hypercortisolism' with a success rate of $100 \%$, immediately.

- The success, furthermore, is permanent, in almost all patients. Rare patients, less than $10 \%$, however, may resume some endogenous cortisol secretion sometimes to the point that 'chronic hypercortisolism' may recur years after a total bilateral adrenalectomy. This is caused by adrenal rests that have escaped the surgeon operation.

- The laparoscopic surgical approach is now the standard, and experienced teams have reported mortality rates of zero, but with some definitive morbidity. It is indeed a difficult surgical procedure, which should be restricted to referral centers. Several recent series have shown that the quality of life of these operated patients was clearly improved, and similar to or better than that after a - somewhat - less major surgical procedure (transsphenoidal surgery) (21).

- Yet,

- These patients become Addisonian: they will need life-long steroid coverage with glucocorticoids and mineralocorticoids, and its unavoidable constraints, need for adaptation, education and the risk of acute adrenal insufficiency.

- The pituitary tumor, of course, is still present. However, the probability of full blown Nelson's syndrome is minimized in the modern era, because of the common availability of ACTH measurement and pituitary MRI, essential tools which were obviously lacking in the 1950 s when Don Nelson established 'his' syndrome. Nelson 
Syndrome was originally defined by invasive tumor progression of a pituitary ACTH-producing adenoma following bilateral adrenalectomy. Currently, we can precisely follow the 'corticotroph tumor progression' in all patients undergoing bilateral adrenalectomy before the tumor has extended to the point that it has become symptomatic. Recent studies (22) have shown that: (1) corticotroph tumor progression is highly variable; (2) it can be detected early by plasma ACTH and pituitary MRI follow-up; (3) when it occurs, the early stages are manageable and (4) it is not accelerated by pregnancy. Preventive pituitary radiotherapy after adrenalectomy has been debated, but does not seem to be a validated, or necessary, procedure.

\section{Why not combine!}

Many authors have thoughtfully combined several treatments, acting at different levels of the pituitaryadrenal axis (Fig. 7), so as to improve effectiveness and reduce adverse events. For example, patients undergoing pituitary radiotherapy and treated concomitantly with

\section{Treatment Options \\ ("The Cushingame ")}

some sort of steroid synthesis inhibitor or Mitotane, while awaiting for the full effect of radiation therapy.

Two 'combination' approaches have been documented in rather convincing studies, in two contrasting situations:

- In patients with severe Cushing's disease, ruling out any surgical approach (cardiac failure, recent pulmonary embolism, etc.), a 'tritherapy' was used. The two steroid inhibitors, ketoconazole and metyrapone, acting at different steps of steroidogenesis and small doses of Mitotane, acting as a slow adrenolytic were 'simultaneously' administered (23). This 'cocktail' proved highly effective, normalizing extremely high initial UC within a few days. Both ketoconazole and metyrapone could be withdrawn after a few weeks, at a time when Mitotane had started its delayed adrenolytic action, eliminating the risk of escape phenomena.

- In an opposite situation, patients with classic Cushing's disease (not severe) were 'sequentially' treated with up to three different drugs, starting with pasireotide first, adding cabergoline and finally ketoconazole, as needed (24). Under this sequential approach, most patients (15 of 17) were eventually controlled (UC normalized).
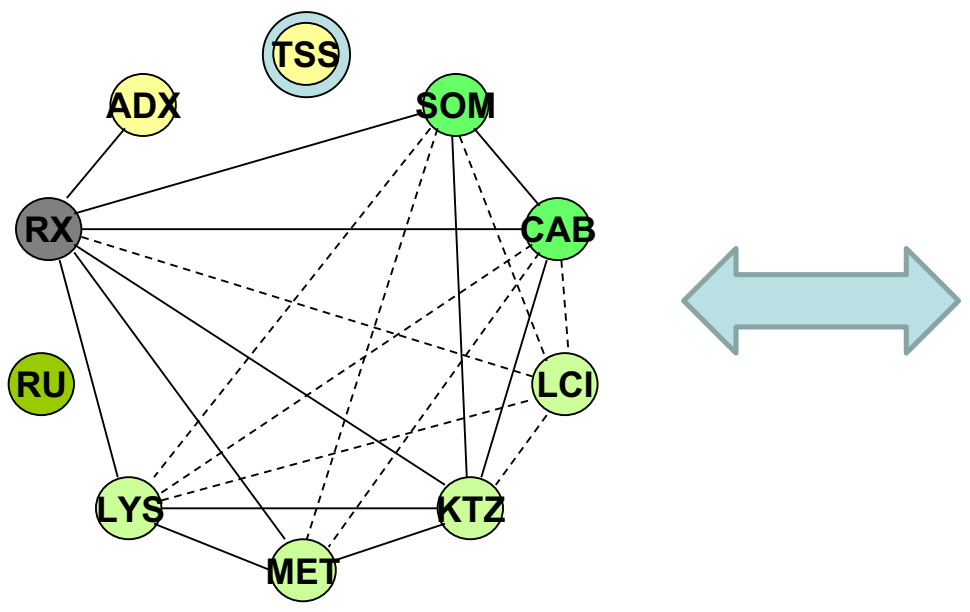

\section{The patient}

- Severity : do we have time ?

- Need for rapid success

- Tumor threat

- Prior treatments

- Age

- Sex

- Pregnancy

- Distance

- Preference (shots ? pills ?)

- Drug availability

- Drug cost

- Follow-up

Figure 7

Squaring the circle: The 'cushingame' ... in search of the 'taylored treatment'. Or how to interface the too-many therapeutic options for Cushing's disease, and their combinations, and the too-many individual differences between patients. ADX, total bilateral adrenalectomy; CAB, cabergoline; KTZ, ketoconazol; LCI, LCI 699 or osilodrostat; LYS, mitotane; MET, metyrapoe; RU, RU 486 or mifepristone; RX, pituitary radiotherapy; SOM, somatostatin analog; TSS, transsphenoidal surgery. 
With so many options now available to treat Cushing's disease, an experienced endocrinologist can use his/ her imagination in a sort of 'Cushingame' where, for a given patient, the best possible combination has to be identified and selected (Fig. 7) - a difficult game.

\section{When are limitations counterbalanced by severity?}

Several factors contribute to the severity of Cushing's disease:

- The high levels of circulating cortisol, which may actually be an immediate vital threat to survival, through infectious, cardiovascular, psychiatric complications.

- The duration of the disease, which may have been unknown for years; a late diagnosis will not allow total recovery of debilitating features/complications, which may have accumulated over the years.

- The tumoral threat, although this is rarely an immediate problem in the majority of the cases.

These conditions evidently define the therapeutic strategy:

- When an urgent and rapid control of the hypercortisolism is vitally needed, the limitations of a 'combined' medical approach or even a rescue bilateral adrenalectomy may appear legitimate if the pituitary surgery fails or seems without hope.

- In contrast, in 'mild' forms of 'chronichypercortisolism', it is not obvious to anticipate the benefit of various medical options in comparison with their tolerance and possible AEs. Some patients have severe stigmata of long-standing undiagnosed hypercortisolism with biological counterparts (UC), which appear in sharp discordance, i.e. relatively mild. These not uncommon situations are particularly difficult to manage: we do not expect a dramatic clinical change, and drug efficacy and evaluation of 'adrenal insufficiency' episodes are extremely difficult to assess.

\section{And at the end the treatment should be: 'tailored in each individual patient'}

As already stated, when a given disease has so many therapeutic options, it is not reassuring at all.

Cushing's disease patients are different; and it is remarkable that in one of the latest (among many) published guidelines for the treatment of Cushing's disease patients (25), with the official support of the
American Endocrine Society, a selected group of experts, eventually state 'When surgery is not possible or is noncurative, the choice of second-line therapy must take into account patient preferences; treatment goals; biochemical control; the size and location of residual tumors; the urgency to treat; other medications (drug-drug interactions); the patient's personal history; the method of delivery, side effects, and cost of medication; gender; age; and the availability of medical therapies'. (Other considerations could even be added Fig. 7, 'Squaring the circle').

Just another conclusion, in another review, in the same Journal (26): 'Medical therapy for Cushing's disease can be targeted at different levels and should be tailored in each individual patient. Future studies should examine the optimal dose and combination of medical treatment modalities for Cushing's disease'.

Really a difficult game! For the doctor - and the 'guideliners' - who can cope! However, for the patient, who endure the maleficence of the disease, and - with time - realize that medicine, as modern and as 'personalized' it can be, still has limitations.

\section{Future directions}

\section{Some progress, recently}

- Total bilateral adrenalectomy is now performed taking a laparoscopic approach with very small surgical risk.

- Pasireotide obtained the first official authorization for a drug acting directly at the pituitary, with a low efficiency rate.

- Mifepristone was authorized in the United States, with some restrictions with its not-so-easy new mode of action.

- LCI 699 is a new CYP11B1 inhibitor, which seems to be promising in terms of efficacy and low rate of AEs, but still under development, and not radically different from Metyrapone.

All this 'progress' means one thing: more progress is needed!

\section{The pituitary adenoma is a reasonable obsession}

For obvious theoretical reasons, no treatment should be better than that which specifically controls/ablates the cause of Cushing's disease: The ACTH-secreting pituitary adenoma. 
Can we improve the efficiency of the pituitary surgery/radiotherapy?

- Better and more precise (and intra-operative) MRI imaging of the pituitary?

- More efficient surgical approaches, through endoscopy and better microscopic visualization?

- More focused radiotherapeutical techniques?

What other endocrine tumors have taught and teach us

- The 'toxic thyroid nodule' and the 'toxic ACTHsecreting pituitary adenoma':

- The toxic thyroid nodule is a hypersecretory endocrine tumor that has long found its 'holy grail'. Nothing is as easy, as costless, and as rewarding as treating a toxic thyroid nodule. A single dose of RAI (radioactive iodine) in outpatients always and definitely eliminates the hyperthyroidism, and subsequently, restores a fully normal pituitary-thyroid axis.

- This non-surgical approach is feasible because;

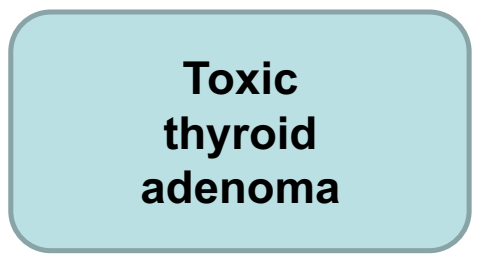

Benign

Clonal

Conserved normal

- and specificphenotypic features : NIS

Ablation restore normal function of transiently suppressed normal cells : Surgery RAl
- We know we are dealing with a clonal, benign tumor

- A tumor benign enough that it has kept many of its normal (and rather specific) differentiated phenotypic features.

- The expression of the sodium-iodide symporter (NIS) allows RAI to accumulate within the tumor cells, enhancing the efficacy of RAI therapy in a specific, organtargeted way.

- At the same time, because it all happens in a negative feedback system, normal, nontumoral thyroid cells are preserved.

- This will allow subsequent recovery of the overall thyroid function.

- Nothing resembles the 'toxic thyroid nodule' more than the 'toxic ACTH-secreting pituitary adenoma' of Cushing's disease (Fig. 8).

- A benign, clonal tumor, within a negative feedback system (27).

- Which has conserved most of its normal differentiated phenotypic features (GPCR

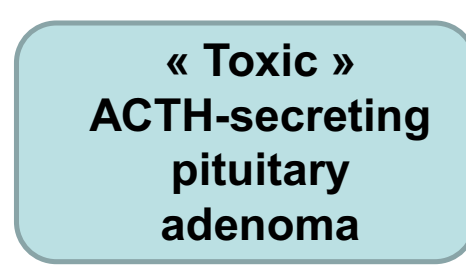

\author{
Benign
}

Clonal

\section{Conserved normal \\ - and specific- phenotypic features $X$ ?}

\section{Ablation restore normal function of transiently suppressed normal cells : Surgery Targeting through $\mathrm{X}$ ?}

Figure 8

Comparing the pathophysiologies of the toxic thyroid adenoma and the 'toxic' ACTH-secreting pituitary adenoma. NIS, sodium iodide symporter; RAl, radioactive iodine therapy; $\mathrm{X}$, the molecular target to be found in the ACTH-secreting pituitary adenoma. 
expression, glucocorticoid receptivity, prohormone convertases). Some of them being rather specific (28).

- Resuming completely normal pituitary adrenocortical function after ablation of the tumor (29).

- Yet! The grail is still to be found, which would allow to take control of the tumor, medically. Better knowledge of the normal 'biology' of the ACTH cell should help: Hopefully, most endocrine tumors - and this is particularly true for the pituitary - are benign and have kept many features of their initial - normal - phenotype. In some cases it may be judiciously taken into consideration to direct the most efficacious treatments: Besides the maintained NIS expression in thyroid tumors as a basis for RAI treatment, maintained DA2-R expression in PRL-secreting pituitary adenomas is the basis for the highly effective dopaminergic treatment of these adenomas. In ACTH-secreting pituitary adenomas, no such approach, yet!

- On the other hand, acquired phenotype of the tumor...may provide us with new targets

- Major progress has been made in the last years in the molecular understanding of endocrine tumors pathophysiology.

- In many cases, germ line or sporadic mutations have clearly pointed-out molecular mechanisms leading to tumor growth. This is true for benign and highly differentiated tumors such as adrenocortical adenomas leading to Cushing's syndrome or Conn's adenoma, through the activations of the cAMP pathway or the calcium signaling pathway, respectively (30). The hypoxia and MAP kinases pathways are involved in most pheochromocytomas (31). In malignant thyroid tumors, the role of BRAF mutations, RET, the MAP kinase pathways have long been identified (32).

- Better knowledge of the 'modified' tumor biology is sometimes of help: BRAF-mutated melanoma, Tyr-kinase mutated GISTs, now provide the therapeutist with targets for efficient new medical treatments (33).

- With regard to the pituitary, we know about the role of Menin and AIP mutations, which nevertheless rarely concern ACTH-secreting adenomas. The only reported, so far, recurrent mutation in ACTH-secreting pituitary adenomas is that of USP8 (34), which has no therapeutic correlate yet, although it may suggest that control of the EGF-R might be a clue! Cables, SDHs genes are much more rarely involved.

It is indeed important to discover new molecular targets that would at the same time explain the pathophysiology of ACTH-secreting pituitary adenomas and provide us with potential new and efficient therapeutic approaches.

Yet, we should not neglect to search as well within the repertoire of normal phenotypic traits of these benign and highly differentiated tumors those 'natural' targets that have been preserved and could possibly be used for therapeutic approaches. The examples of the 'toxic thyroid nodule', and more recently, of the prolactinoma are paradigmatic endocrine tumors which have found their 'holy grail' long before the emergence of 'personalized medicine'!

\section{And downstream of the pituitary adenoma}

\section{○ ATR-101}

Mitotane and ATR 101 both apparently share a common mode of action through the inhibition of ACAT1 (35). ATR-101 might have unique advantages over the currents steroid inhibitors (no liver AE as with Ketoconazole, no risk of precursor increase as with Metyrapone or LCI699). Together with its supposed advantages over Mitotane (faster effect, less AE due to its better adrenal specificity). Yet, more to be learnt.

○ Anti-ACTH (MC2-R antagonists)

Inhibiting the direct action of ACTH at the level of the adrenally expressed ACTH receptor MC2$\mathrm{R}$, would theoretically add several advantages: immediate response; no expected $\mathrm{AE}$, due to the extreme specificity of the mode of action; no precursor problem. Aldosterone secretion normally maintained (36). Yet, how to precisely monitor the cortisol secretion? Should we anticipate an ACTH rebound effect?

\section{- SEGRA}

SElective Glucocorticoid Receptor Agonists (SEGRA) have been developed with the idea to create new molecules the 'glucocorticoid' action of which is dissociated on different target cells. Such a compound has been synthesized which decrease ACTH plasma levels but has no - or little - effect on liver (37). One immediately sees the benefit that could possibly be obtained in Cushing's disease patients. 


\section{○ And...}

New somatostatin analogs, short interfering RNA oligonucleotides preventing transcription of the POMC gene, retinoic acid to inhibit POMC gene transcription, antagonists of SF1, inhibitors of EGF-R tyrosine kinase activity to decrease POMC gene expression and tumor growth, new antagonists to the glucocorticoid receptor type 2 , new inhibitors of steroid biosynthesis are in the basket of imaginative researchers. Temozolomide has its use restricted to the rare malignant pituitary tumors.

\section{Conclusion}

'...Striking clinical effects...produced...by minute pituitary adenomas' as Harvey Cushing stated when he discovered the cause of his disease (38).

Forty years after Salassa's and Tyrrell's (2, 3) groups 'cured' the first patients by pituitary surgery, we still do not know how to take control of them medically: These 'minute' adenomas remain a 'huge', and 'long-lasting', endocrinological challenge.

\section{Declaration of interest}

The authors declare that there is no conflict of interest that could be perceived as prejudicing the impartiality of this review.

\section{Funding}

In the last three years, the author has had financial links with the following pharmaceutical companies (HRA-Pharma, Novartis, IPSEN) for activities in conferences and scientific boards. This work did not receive any specific grant from any funding agency in the public, commercial or non-for-profit sector.

\section{References}

1 Bertagna X \& Guignat L. Approach to the Cushing's disease patient with persistent/recurrent hypercortisolism after pituitary surgery. Journal of Clinical Endocrinology and Metabolism 201398 1307-1318. (https://doi.org/10.1210/jc.2012-3200)

2 Salassa RM, Laws ER Jr, Carpenter PC \& Northcutt RC. Transsphenoidal removal of pituitary microadenoma in Cushing's disease. Mayo Clinic Proceedings 197853 24-28.

3 Tyrrell JB, Brooks RM, Fitzgerald PA, Cofoid PB, Forsham PH \& Wilson CB. Cushing's disease. Selective trans-sphenoidal resection of pituitary microadenomas. New England Journal of Medicine 1978298 753-758.

4 Krieger DT, Amorosa L \& Linick F. Cyproheptadine-induced remission of Cushing's disease. New England Journal of Medicine 1975 293 893-896. (https://doi.org/10.1056/NEJM197510302931802)

5 Petersenn S, Newell-Price J, Findling JW, Gu F, Maldonado M, Sen K, Salgado LR, Colao A, Biller BM \& Pasireotide B2305 Study Group. High variability in baseline urinary free cortisol values in patients with Cushing's disease. Clinical Endocrinology 201480 261-269. (https://doi.org/10.1111/cen.12259)

6 Guarnotta V, Amato MC, Pivonello R, Arnaldi G, Ciresi A, Trementino L, Citarrella R, Iacuaniello D, Michetti G, Simeoli C et al. The degree of urinary hypercortisolism is not correlated with the severity of Cushing's syndrome. Endocrine 201755 564-572. (https:// doi.org/10.1007/s12020-016-0914-9)

7 Colao A, Petersenn S, Newell-Price J, Findling JW, Gu F, Maldonado M, Schoenherr U, Dipl B, Mills D, Salgado LR et al. A 12-month phase 3 study of pasireotide in Cushing's disease. New England Journal of Medicine 2012366 914-924. (https://doi. org/10.1056/NEJMoa1105743)

8 Pivonello R, De Martino MC, Cappabianca P, De Leo M, Faggiano A, Lombardi G, Hofland LJ, Lamberts SW \& Colao A. The medical treatment of Cushing's disease: effectiveness of chronic treatment with the dopamine agonist cabergoline in patients unsuccessfully treated by surgery. Journal of Clinical Endocrinology and Metabolism 200994 223-230. (https://doi.org/10.1210/jc.2008-1533)

9 Daniel E, Aylwin S, Mustafa O, Ball S, Munir A, Boelaert K, Chortis V, Cuthbertson DJ, Daousi C, Rajeev SP et al. Effectiveness of metyrapone in treating Cushing's syndrome: a retrospective multicenter study in 195 patients. Journal of Clinical Endocrinology and Metabolism 2015100 4146-4154. (https://doi.org/10.1210/jc.20152616)

10 Bertagna X, Pivonello R, Fleseriu M, Zhang Y, Robinson P, Taylor A, Watson CE, Maldonado M, Hamrahian AH, Boscaro M et al. LCI699, a potent $11 \beta$-hydroxylase inhibitor, normalizes urinary cortisol in patients with Cushing's disease: results from a multicenter, proof-ofconcept study. Journal of Clinical Endocrinology and Metabolism 2014 99 1375-1383. (https://doi.org/10.1210/jc.2013-2117)

11 Fleseriu M, Pivonello R, Young J, Hamrahian AH, Molitch ME, Shimizu C, Tanaka T, Shimatsu A, White T, Hilliard A et al. Osilodrostat, a potent oral $11 \beta$-hydroxylase inhibitor: 22 -week, prospective, phase II study in Cushing's disease. Pituitary 201619 138-148. (https://doi.org/10.1007/s11102-015-0692-z)

12 Castinetti F, Guignat L, Giraud P, Muller M, Kamenicky P, Drui D, Caron P, Luca F, Donadille B, Vantyghem MC et al. Ketoconazole in Cushing's disease: is it worth a try? Journal of Clinical Endocrinology and Metabolism 201499 1623-1630. (https://doi.org/10.1210/ jc.2013-3628)

13 Baudry C, Coste J, Bou Khalil R, Silvera S, Guignat L, Guibourdenche J, Abbas H, Legmann P, Bertagna X \& Bertherat J. Efficiency and tolerance of mitotane in Cushing's disease in 76 patients from a single center. European Journal of Endocrinology 2012 167 473-481. (https://doi.org/10.1530/EJE-12-0358)

14 Sbiera S, Leich E, Liebisch G, Sbiera I, Schirbel A, Wiemer L, Matysik S, Eckhardt C, Gardill F, Gehl A et al. Mitotane inhibits Sterol-O-Acyl transferase 1 triggering lipid-mediated endoplasmic reticulum stress and apoptosis in adrenocortical carcinoma cells. Endocrinology 2015156 3895-3908. (https://doi.org/10.1210/ en.2015-1367)

15 Chortis V, Taylor AE, Schneider P, Tomlinson JW, Hughes BA, O’Neil DM, Libé R, Allolio B, Bertagna X, Bertherat J et al. Mitotane therapy in adrenocortical cancer induces CYP3A4 and inhibits $5 \alpha$-reductase, explaining the need for personalized glucocorticoid and androgen replacement. Journal of Clinical Endocrinology and Metabolism 201398 161-171. (https://doi.org/10.1210/jc.2012-2851)

16 Hahner S \& Fassnacht M. Mitotane for adrenocortical carcinoma treatment. Current Opinion in Investigational Drugs 20056 386-394.

17 Bertagna X, Bertagna C, Luton JP, Husson JM \& Girard F. The new steroid analog RU 486 inhibits glucocorticoid action in man. Journal of Clinical Endocrinology and Metabolism 198459 25-28. (https://doi. org/10.1210/jcem-59-1-25)

18 Fleseriu M, Biller BM, Findling JW, Molitch ME, Schteingart DE, Gross C \& on behalf of the SEISMIC Study Investigators. The SEISMIC Study Investigators include: mifepristone, a glucocorticoid 
receptor antagonist, produces clinical and metabolic benefits in patients with Cushing's syndrome. Journal of Clinical Endocrinology and Metabolism 201297 2039-2049. (https://doi.org/10.1210/ jc.2011-3350)

19 Debono M, Harrison RF, Chadarevian R, Gueroult C, Abitbol JL \& Newell-Price J. Resetting the abnormal circadian cortisol rhythm in adrenal incidentaloma patients with mild autonomous cortisol secretion. Journal of Clinical Endocrinology and Metabolism 2017102 3461-3469. (https://doi.org/10.1210/jc.2017-00823)

20 Starke RM, Williams BJ, Vance ML \& Sheehan JP. Radiation therapy and stereotactic radiosurgery for the treatment of Cushing's disease: an evidence-based review. Current Opinion in Endocrinology, Diabetes and Obesity 201017 356-364. (https://doi.org/10.1097/ MED.0b013e32833ab069)

21 Thompson SK, Hayman AV, Ludlam WH, Deveney CW, Loriaux DL $\&$ Sheppard BC. Improved quality of life after bilateral laparoscopic adrenalectomy for Cushing's disease: a 10-year experience. Annals of Surgery 2007245 790-794. (https://doi.org/10.1097/01. sla.0000251578.03883.2f)

22 Assié G, Bahurel H, Coste J, Silvera S, Kujas M, Dugué MA, Karray F, Dousset B, Bertherat J, Legmann P et al. Corticotroph tumor progression after adrenalectomy in Cushing's disease: a reappraisal of Nelson's syndrome. Journal of Clinical Endocrinology and Metabolism 200792 172-179.

23 Kamenicky P, Droumaguet C, Salenave S, Blanchard A, Jublanc C, Gautier JF, Brailly-Tabard S, Leboulleux S, Schlumberger M, Baudin E et al. Mitotane, metyrapone, and ketoconazole combination therapy as an alternative to rescue adrenalectomy for severe ACTH-dependent Cushing's syndrome. Journal of Clinical Endocrinology and Metabolism 201196 2796-2804. (https://doi.org/10.1210/jc.2011-0536)

24 Feelders RA, de Bruin C, Pereira AM, Romijn JA, Netea-Maier RT, Hermus AR, Zelissen PM, van Heerebeek R, de Jong FH, van der Lely AJ et al. Pasireotide alone or with cabergoline and ketoconazole in Cushing's disease. New England Journal of Medicine 362 1846-1848. (https://doi.org/10.1056/NEJMc1000094)

25 Nieman LK, Biller BMK, Findling JW, Hassan Murad M, NewellPrice J, Savage MO \& Tabarin A. Treatment of Cushing's syndrome: an Endocrine Society Clinical Practice Guideline. Journal of Clinical Endocrinology and Metabolism 2015100 2807-2831. (https://doi. org/10.1210/jc.2015-1818)

26 Feelders RA \& Hofland LJ. Medical treatment of Cushing's disease. Journal of Clinical Endocrinology and Metabolism 201398 425-438. (https://doi.org/10.1210/jc.2012-3126)

27 Gicquel C, Le Bouc Y, Luton JP, Girard F \& Bertagna X. Monoclonality of corticotroph macroadenomas in Cushing's disease. Journal of Clinical Endocrinology and Metabolism 199275 472-475.
28 de Keyzer Y, René P, Beldjord C, Lenne F \& Bertagna X. Overexpression of vasopressin (V3) and corticotrophin-releasing hormone receptor genes in corticotroph tumours. Clinical Endocrinology 199849 475-482. (https://doi.org/10.1046/j.13652265.1998.00560.x)

29 Guilhaume B, Bertagna X, Thomsen M, Bricaire C, Vila-Porcile E, Olivier L, Racadot J, Derome P, Laudat MH, Girard F et al. Transsphenoidal pituitary surgery for the treatment of Cushing's disease: results in 64 patients and long term follow-up studies. Journal of Clinical Endocrinology and Metabolism 198866 1056-1064. (https://doi.org/10.1210/jcem-66-5-1056)

30 Bertagna X. Genetics of adrenal diseases in 2014: genetics improves understanding of adrenocortical tumours. Nature Reviews Endocrinology 201511 77-78. (https://doi.org/10.1038/ nrendo.2014.215)

31 Fishbein L, Leshchiner I, Walter V, Danilova L, Robertson AG, Johnson AR, Lichtenberg TM, Murray BA, Ghayee HK, Else T et al. Comprehensive molecular characterization of pheochromocytoma and paraganglioma. Cancer Cell 201731 181-193. (https://doi. org/10.1016/j.ccell.2017.01.001)

32 Integrated genomic characterization of papillary thyroid carcinoma. Cancer Genome Atlas Research Network. Cell 2014159 676-690.

33 Devji T, Levine O, Neupane B, Beyene J \& Xie F. Systemic therapy for previously untreated advanced BRAF-mutated melanoma: a systematic review and network meta-analysis of randomized clinical trials. JAMA Oncology 20173 366-373. (https://doi.org/10.1001/ jamaoncol.2016.4877)

34 Reincke M, Sbiera S, Hayakawa A, Theodoropoulou M, Osswald A, Beuschlein F, Meitinger T, Mizuno-Yamasaki E, Kawaguchi K, Saeki Y et al. Mutations in the deubiquitinase gene USP8 cause Cushing's disease. Nature Genetics 201547 31-38. (https://doi.org/10.1038/ng.3166)

35 LaPensee CR, Mann JE, Rainey WE, Crudo V, Hunt SW 3rd \& Hammer GD. ATR-101, a selective and potent inhibitor of acyl-CoA acyltransferase 1, induces apoptosis in H295R adrenocortical cells and in the adrenal cortex of dogs. Endocrinology $2016 \mathbf{1 5 7}$ 1775-1788. (https://doi.org/10.1210/en.2015-2052)

36 Clark AJ, Forfa R, Hussain M, Jerman J, McIver Ed, Taylor D \& Chan L. ACTH antagonists. Frontiers in Endocrinology 20167101.

37 Schäcke H, Schottelius A, Döcke WD, Strehlke P, Jaroch S, Schmees N, Rehwinkel H, Hennekes H \& Asadullah K. Dissociation of transactivation from transrepression by a selective glucocorticoid receptor agonist leads to separation of therapeutic effects from side effects. PNAS 2004101 227-232.

38 Cushing $\mathrm{H}$. The basophil adenomas of the pituitary body and their clinical manifestations. Bulletin of the Johns Hopkins Hospital 193250 137-195.

Received 30 January 2018

Revised version received 7 February 2018

Accepted 20 February 2018 